\title{
Formation of water nanodrops in cellulose impregnated with insulating oil
}

\author{
Paweł Żukowski • Tomasz N. Kołtunowicz • \\ Konrad Kierczyński · Jan Subocz • Marek Szrot
}

Received: 6 May 2014 / Accepted: 2 January 2015/Published online: 10 January 2015

(C) The Author(s) 2015. This article is published with open access at Springerlink.com

\begin{abstract}
This article presents results on the DC conductivity of moist pressboard impregnated with insulating oil and its dependence on the moisture and temperature of the samples. The transfer of charges was found to take place because of electron hopping between potential wells produced by water nanodrops. The average dimension of the nanodrops was around $2.32 \mathrm{~nm}$, forming approximately 220 water molecules.
\end{abstract}

Keywords Pressboard · Insulating oil · Moisture · DC conductivity $\cdot$ Electron hopping $\cdot$ Water nanodrops

\section{Introduction}

The article investigated the DC conductivity of cellulose impregnated with insulating oil, with water concentrations in the range $1.5-6.7 \mathrm{wt} \%$. This is a

P. Żukowski · T. N. Kołtunowicz · K. Kierczyński ( $₫)$ Department of Electrical Device and High Voltage Technology, Faculty of Electrical Engineering and Computer Science, Lublin University of Technology, 38a, Nadbystrzycka Street, 20-618 Lublin, Poland e-mail: k.kierczynski@pollub.pl

J. Subocz

Department of Electrotechnology and Diagnostics, West Pomeranian University of Technology, 37 Sikorskiego Street, 70-313 Szczecin, Poland

\section{Szrot}

Power Engineering Research Centre Ltd., 9 Lotnikow Street, 41-949 Piekary Slaskie, Poland seemingly unusual object, but it has been widely used in constructing insulation for high-voltage power transformers for decades. After production, the power transformer was vacuum-dried to the moisture level in the cellulose insulation, which was higher than $0.8 \mathrm{wt} \%$. Then the transformer was filled with insulating oil of moisture not higher than $2 \mathrm{ppm}$. The insulating oil impregnated the dried paper and pressboard. Operating the power transformer for a long time, the moisture in the cellulose gradually rose to more than $5 \mathrm{wt} \%$. There are two primary sources of moisture entering the cellulose-insulated component of transformers. Moisture partially creeps from the outside and partially appears directly in cellulose as one of the sources of deterioration processes, namely pyrolysis, hydrolysis and oxidation.

Until now, it was thought that in an electrotechnical paper and pressboard impregnated with oil, the DC conductivity occurred by ion conductivity, which can be described by the Pool-Frank or Schottky models, presented, for example, in the paper by Mott and Gurney (1950). Recently, in a study by Żukowski et al. (2014), it was found that the conductivity depends on moisture much more strongly than on the linear dependence described by the ion conductivity models. This article presents the DC conductivity of damp pressboard impregnated with insulated oil, which was determined by the moisture content and occurred because of electron hopping (tunneling). There are models based on the hopping mechanism of 
electrons describing DC (Mott and Davis 1979; Shklovsky and Efros 1984) and AC conductivity (Kołtunowicz et al. 2013; Koltunowicz et al. 2014) in semiconductors or metal-insulator nanocomposites with high precision. The result obtained in a study by Żukowski et al. (2014) described the possibility to unravel the problem of the moisture level in oilimpregnated cellulose. Taking into account the quantum mechanics potential of the wells between which tunneling takes place, they are close to atomic size (nanometrical). This means that the water in oilimpregnated cellulose may be in the form of single molecules or small associations-nanodrops. Therefore, in this article we used DC conductivity analysis to determine the sizes of water nanodrops in moist pressboard impregnated with insulating oil.

\section{Research subject and DC conductivity measurement method}

Weidemann electrotechnical pressboard T IV with a density of $1,000 \mathrm{~kg} / \mathrm{m}^{3}$ was used. We used a wellknown method of sample preparation, which was described in by Gäfvert et al. (1997). Samples of $215 \times 215-\mathrm{mm}^{2}$ size with 1 - or 2-mm thickness were dried in a vacuum chamber at the temperature of $353 \mathrm{~K}$ until their weight stopped reducing. The method of chemical titration (the so-called KFT method) required the sample moisture $X$ to be measured, and it was $X \approx(0.575 \pm 0.025) \mathrm{wt} \%$. Then, the samples were saturated with moisture from free air at the temperature $T$ of $295 \mathrm{~K}$ at relative air saturation moisture $\zeta$ equal to $(70 \pm 5) \%$. The weight of the samples was monitored and controlled until moisture saturation was reached. This was followed by impregnating the samples with insulated oil at the $T=348 \mathrm{~K}$ and at relative air saturation moisture $\zeta$ of $15 \%$ for $72 \mathrm{~h}$. The pressboard impregnation with oil and equalization of moisture within its volume were done during this process. Conductivity of the pressboard was measured using a flat-plate three-electrode configuration (Fig. 1). The voltage electrode (top) was loaded using $30 \mathrm{~kg}$ ballast. The electrode assembly including the sample was placed in the oil bath in a climatic chamber at a temperature stabilized to an accuracy of $\pm 0.1 \mathrm{~K}$. The measurements were performed using a 6517A Keithley meter under $E=10 \mathrm{kV} / \mathrm{m}$ electric field strength.

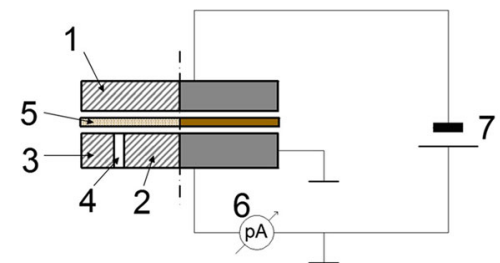

(a)

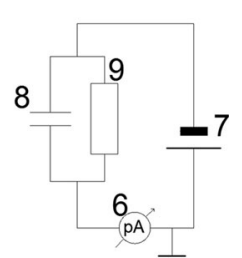

(b)
Fig. 1 Three-electrode measurement system (a). 1 Voltage electrode; 2 measuring electrode; 3 protective electrode; 4 insulator; 5 examined pressboard; 6 Keithley 6517A pikoammeter; 7 DC voltage source (Keithley 6517A); parallel equivalent circuit of the measurement system (b). 8 Capacitor with ideal dielectric with relative permittivity $\varepsilon_{\mathrm{r}} ; 9$ resistor with DC conductivity $\sigma$

The measurement system, presented in Fig. 1a, has two electrodes with large surfaces (about $200 \mathrm{~cm}^{2}$ ). A sample of moist pressboard impregnated with insulating oil was placed between these electrodes using a parallel-plate capacitor. The dielectric in this capacitor has relative permittivity $\varepsilon_{\mathrm{r}}$ and DC conductivity $\sigma$. The equivalent circuit of this system is parallel (Fig. 1b). After the DC voltage $U$ has been connected to the measuring system in the dielectric, two parallel phenomena take place-capacitor charging and conduction current. As time passes, the capacitor voltage increases and the capacitor charging current intensity decreases, as is shown in Fig. 2. When the capacitor voltage reaches the supply voltage value $U$, the charging current falls to zero and the conduction current $I_{0}$ starts flowing through the measurement system, which is only related to the nonzero conductivity value of the pressboard. These current values stay constant, as can be seen for large time values in

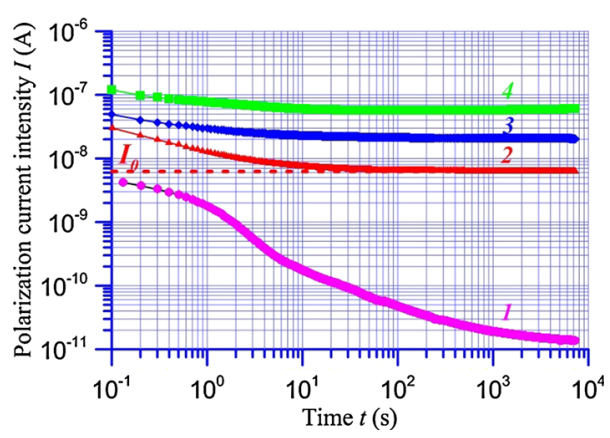

Fig. 2 Measurement results of the polarization current intensity versus time for the pressboard samples measured at $T=318 \mathrm{~K}$ of moisture $11.8 \mathrm{wt} \%, 23.2 \mathrm{wt} \%, 34.0 \mathrm{wt} \%$ and $45.1 \mathrm{wt} \%$ 
Fig. 2. Determination of the $I_{0}$ value from the time charts allows calculating the DC conductivity value of the pressboard using formula (1).

Figure 2 shows the relationship between the current intensity running through the pressboard and the time measured at the temperature $318 \mathrm{~K}$ for different moisture levels (1.8-5.1 wt\%). Similar relationships were obtained for the temperature $297 \mathrm{~K}$, and conductivity of the samples was calculated by the following equation:

$\sigma=\frac{I_{0}}{\mathrm{SE}}$,

where $I_{0}$ is the fixed value of the current intensity, $E$ is the electric field intensity, and $S$ is the area of the measuring electrode.

The method for determining the $I_{0}$ value is shown in Fig. 1 for one of the attempts.

\section{Result analysis of the DC conductivity measurements}

As is shown in this article (Żukowski et al. 2014), in moist pressboard impregnated with transformer insulating oil, the DC conductivity dependence on the moisture content is much stronger than on the linear function, and the temperature dependence on conductivity is exponential.

As follows from the study by Shklovsky and Efros (1984), only in the case of tunneling of electrons between the nearest potential wells does this occur very strongly, i.e., exponential dependence of the conductivity on the concentration of potential wells $N_{\mathrm{o}}$. For analysis of the temperature dependence on conductivity and charges and potential wells concentrations in the case of electron tunneling, the dependence given in the paper by Ravich and Nemov (2002) should be used:

$\sigma(r, T=\mathrm{const})=\sigma_{0} \exp \left(-\frac{\beta \cdot r}{R_{0}}-\frac{\Delta E}{k \cdot T}\right)$,

where $r$ is the average distance between potential wells; $R_{0}$ is a position radius of a wave function of a hopping electron; $\beta$ is a numeric factor ranging $\approx(1.75 \pm 0.05)$ (Shklovsky and Efros 1984), $\Delta E$ is an activation energy of conductivity, and $k$ is the Boltzmann constant.

Initially, it was assumed (Źukowski et al. 2014) that the potential wells were randomly arranged for single water molecules with an average distance of $r_{1}$ separating the water molecules and concentration of $N_{0}$, i.e.,

$r_{1} \cong N_{0}^{-\frac{1}{3}}=\left(\frac{X \cdot \rho}{100 \cdot u \cdot M_{\mathrm{H}_{2} \mathrm{O}}}\right)^{-\frac{1}{3}}$,

where $\rho \approx 1,000 \mathrm{~kg} / \mathrm{m}^{3}$ is the pressboard density, $M_{\mathrm{H}_{2} \mathrm{O}}=18$ is the water molecular mass, $u=1.67 \times 10^{-27} \mathrm{~kg}$ is the atomic mass unit, and $X$ is the moisture, wt\%.

Verification of the relationship in Eq. (2) is a sufficient condition for the occurrence of hopping (tunneling) of electrons between the nearest potential wells in the examined sample. The verification of Eq. (2) first of all takes place in checking the constancy of the activation energy $\Delta E$ value for the whole spectrum of changes in the presence of impurities (in this study, moisture). Based on measurements of DC conductivity for the impregnated pressboard at temperatures of 297 and $318 \mathrm{~K}$, the dependence of the activation energy on the moisture was estimated by the Eq. (2), as shown in Fig. 3 (Żukowski et al. 2014). The figure shows that the activation energy value $\Delta E \approx(0.853 \pm 0.071) \mathrm{eV}$ is relatively independent of the moisture concentration.

Using the experimental results that determined the independence of the activation energy from moisture (distance between water molecules), Eq. (2), in the case of $T=$ const., it can be transformed into:

$$
\begin{aligned}
\log \sigma\left(r_{1}, T=\mathrm{const}\right) & =\left[\log \sigma_{0}-\frac{\Delta E}{k T}\right]-\frac{\beta}{R_{0}} r_{1} \\
& =-\frac{\beta}{R_{0}} r_{1}+C
\end{aligned}
$$

where $C=\left[\log \sigma_{0}-\frac{\Delta E}{k T}\right]$.

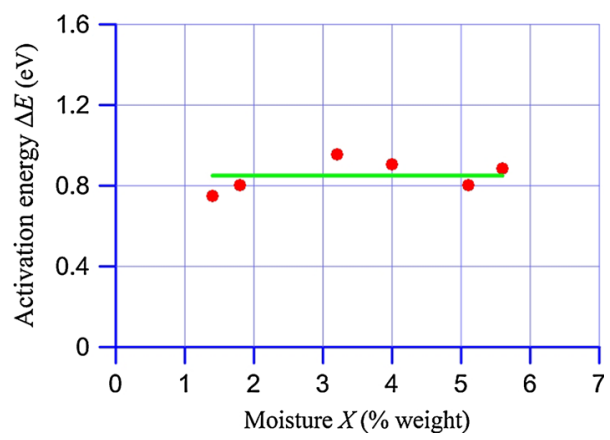

Fig. 3 Calculated results of the activation energy of the pressboard conductivity versus moisture concentration $X$ 
Then the experimental values of conductivity using $\left\{\log \sigma, r_{1}\right\}$ were plotted in Fig. 3. In a semilogarithmic coordinate system, the dependence (4) appears to be a decreasing linear function.

Figure 3 shows the experimental results of DC conductivity of the pressboard versus the distance between water molecules at the temperatures of 297 and $318 \mathrm{~K}$. The figure also shows the results of approximation of the experimental values by the least squares method.

Figure 3 shows that the average value of the slopes $\beta / R_{0} \approx(15.651 \pm 0.015)$, the dependence of $\log \sigma$ on $r_{1}$, for both measured temperatures are diminishing linear functions of equal slopes (i.e., slopes $\beta /$ $R_{0} \approx 15.666 \pm 0.015$ and $15.635 \pm 0.015$ for 297 and $318 \mathrm{~K}$, respectively; the uncertainty limit is $<0.1 \%$ ). The coefficients of determination of $R^{2}$ approximation using the least squares method are close to the unit value, i.e., 0.979 and 0.994 for 297 and $318 \mathrm{~K}$, respectively, which shows a very high accuracy of approximation.

The study by Shklovsky and Efros (1984) reported that $\beta \approx(1.75 \pm 0.05)$, as was assumed in this article, where the potential wells representing a single water molecule were determined from the waveforms shown in Fig. 4. The experimental value of the position radius of the wave function of a hopping electron is $R_{0} \approx(0.112 \pm 0.003) \mathrm{nm}$. When single water molecules are present, then electron tunneling can take place between the doubly and negatively charged oxygen ions, and the ionic radius determined by X-ray is $R_{\mathrm{r}}=0.135 \mathrm{~nm}$ (Van Vlack 1972). The position radius of the outer-shell electron of the ion

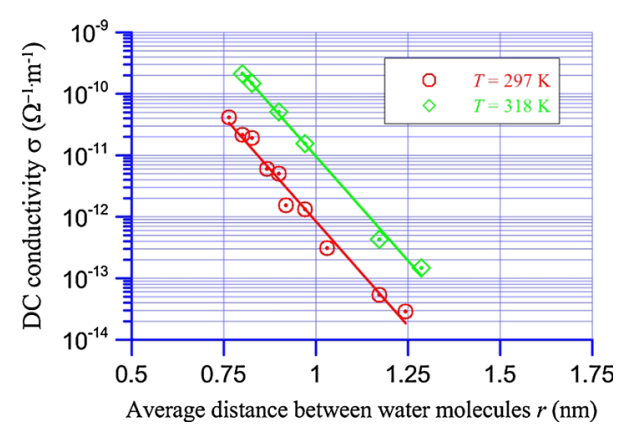

Fig. 4 Measurement results of DC conductivity of the pressboard versus the average distance between water molecules $r_{1}$ at temperatures of 297 and $318 \mathrm{~K}$. The figure also shows the results of approximation of the experimental values by the least squares method placed in a dielectric medium (Shklovsky and Efros 1984) should be larger than $R_{\mathrm{r}}$, i.e.,

$R_{0}>R_{\mathrm{r}}$.

Comparing the experimental results achieved in this study, i.e., $R_{0} \approx(0.112 \pm 0.003) \mathrm{nm}$ and the radius determined by X-ray $R_{\mathrm{r}}=0.135 \mathrm{~nm}$, revealed the opposite inequality compared to Eq. (5). This can be explained by considering water molecules forming nanodrops that contain on average $n$ water molecules. This caused a decrease in the number of drops in comparison with the number of water molecules and an increase in the distance between the drops as a result. The radius $R_{0}^{*}$ of an electron located at the surface of a nanodrop in the pressboard, in the first approximation, can be written as (Shklovsky and Efros 1984):

$R_{0}^{*} \approx \varepsilon_{\mathrm{r}} \cdot R_{\mathrm{r}}$,

where $\varepsilon_{\mathrm{r}}$ is the dielectric permittivity of the pressboard impregnated with oil at high frequencies, and $R_{\mathrm{r}}=0.135 \mathrm{~nm}$ is the radius of the oxygen ion determined by $\mathrm{X}$-ray.

Exchanging the radius $R_{0}$ in Eq. (2) with $R_{0}^{*}$, determined in Eq. (6), should cause an increase of $\beta \cdot r_{1}$ to a value of $\beta \cdot r^{*}$, so that

$\frac{\beta \cdot r^{*}}{R_{0}^{*}} \approx \frac{\beta \cdot r^{*}}{\varepsilon_{\mathrm{r}} R_{\mathrm{r}}}=\frac{\beta \cdot r_{1}}{R_{0}}=15.651 \cdot r_{1}$.

The result of Eq. (7) shows that if water is present in a pressboard, nanodrops will be created at the average distance between them $\left(r^{*}\right)$, which is higher in comparison with the distance between single water molecules $r_{1}$ because:

$r^{*} \cong \frac{15.651 \cdot r_{1} \cdot \varepsilon_{\mathrm{r}} \cdot R_{\mathrm{r}}}{\beta}$.

Considering the value of $r^{*}$, defined in Eq. (8), and transforming Eq. (3) allowed the concentration of water nanodrops $N_{n}$ in a pressboard to be calculated:

$N_{n} \cong\left(r^{*}\right)^{-3} \cong\left(\frac{\beta}{15.651 \cdot r_{1} \cdot \varepsilon_{\mathrm{r}} \cdot R_{\mathrm{r}}}\right)^{3}$.

Resulting from Eq. (3), when single water molecules appear, their concentration is connected with the average distance between them and described by equation:

$N_{0} \cong r_{1}^{-3}$. 


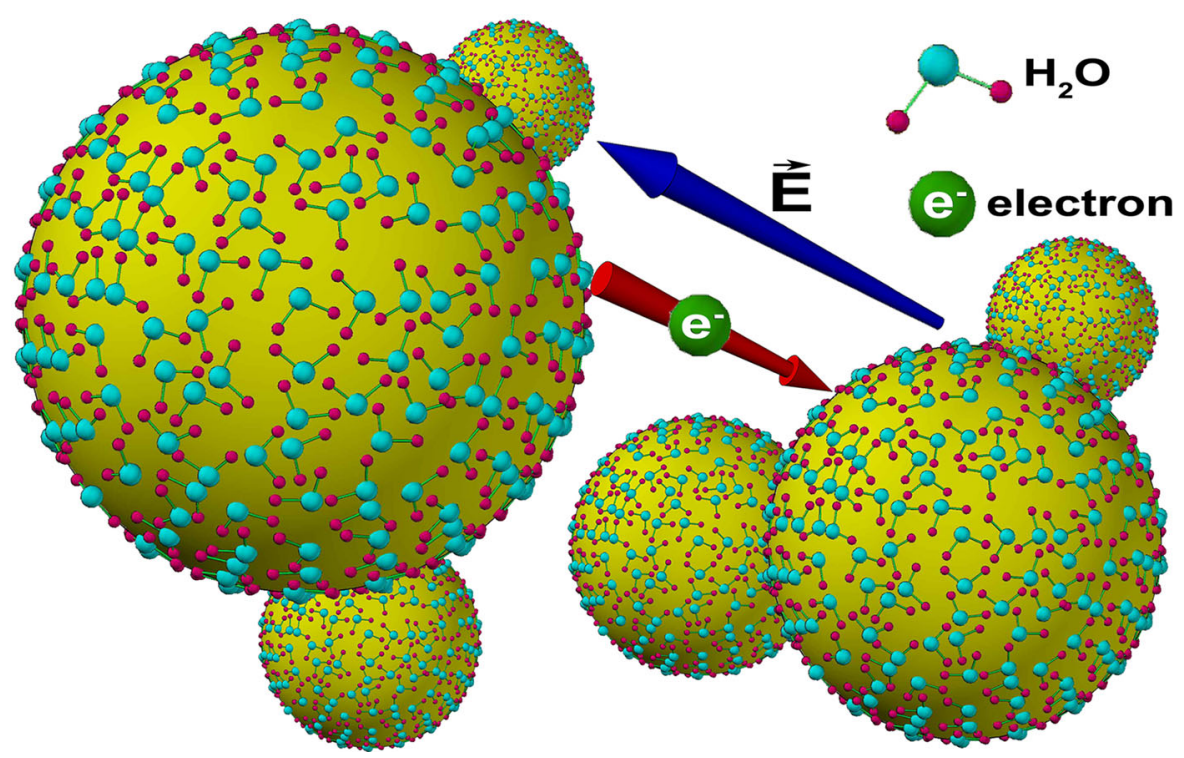

Fig. 5 Nanodrops of water and electron hopping between them

Assuming the number of water molecules in a nanodrop is $n$, and the number of nanodrops, as follows from formula (9), is $N_{n}$, the total number of water molecules:

$N_{0}=n \cdot N_{n}$.

From Eqs. (9), (10) and (11), we can state that the average number of water molecules in a nanodrop can be calculated as:

$n \cong \frac{N_{0}}{N_{n}}=\left(\frac{15.651 \cdot \varepsilon_{\mathrm{r}} \cdot R_{\mathrm{r}}}{\beta}\right)^{3}$

The determined high-frequency permittivity $\varepsilon_{\mathrm{r}}$ (Ekanayake et al. 2006) used in Eqs. (6)-(12) was almost independent on moisture in a pressboard impregnated with insulating oil of $\varepsilon_{\mathrm{r}} \approx 5.0$ value. Substituting the values of $\varepsilon_{\mathrm{r}}, R_{\mathrm{r}}$ and $\beta$ in Eq. (12), the average number of water molecules in a nanodrop can be calculated, and it equals $n \approx 220$. The average diameter of these nanodrops is around $2.32 \mathrm{~nm}$. Figure 5 shows water nanodrops and a hopping electron between them.

The presented experiments reveal that for a device of cellulose impregnated with insulating oil, water created nanodimensional clusters, i.e., nanodrops, related to the fact that water virtually does not dissolve in oil. Below the temperature of $373 \mathrm{~K}$, water does not form chemical compounds with oil. The maximum level of water dissolved in oil does not exceed 200 ppm (0.02 \%) (Oommen 1983), and the remaining water should precipitate in a second phase form. Large differences between the free surface energy of water and oil (respectively 70 and $30 \mathrm{mN} / \mathrm{m}$ at $293 \mathrm{~K}$ temperature) caused the water to create spherical clusters of nanometer dimensions (Pogrebnjak and Beresnev 2012).

\section{Conclusion}

The DC conductivity dependence on a moist pressboard impregnated with insulating oil at various moisture and sample temperature levels is presented in this article. The study verified that the conductivity appeared because of electron hopping (tunneling) between the nearest potential wells created by water nanodrops in a cellulose structure. Results of computations and their analysis were discovered and determined in water nanodrops, which were created in the pressboard impregnated with insulating oil structure with an approximate number of 220 water molecules. The average dimension of the nanodrops was around $2.32 \mathrm{~nm}$.

Acknowledgments Dr. Tomasz N. Koltunowicz (Ph.D., Eng.) and Konrad Kierczynski (M.Sc., Eng.) are participants in the project: "Qualifications for the labour market-employer 
friendly university", cofinanced by the European Union from the European Social Fund.

Open Access This article is distributed under the terms of the Creative Commons Attribution License which permits any use, distribution, and reproduction in any medium, provided the original author(s) and the source are credited.

\section{References}

Ekanayake C, Gubanski SM, Graczkowski A, Walczak K (2006) Frequency response of oil impregnated pressboard and paper samples for estimating moisture in transformer insulation. IEEE Trans Power Deliv 21(3):1309-1317

Gäfvert U, Frimpong G, Fuhr J (1997) Measurement and modeling of dielectric response of composite oil/paper insulation. In: Edelstein A, Cammatata R (eds) Proceedings of 5 th international conference on properties and applications of dielectric materials, Seoul, pp 86-89

Koltunowicz TN, Zukowski P, Milosavljević M, Saad AM, Kasiuk JV, Fedotova JA, Kalinin YuE, Sitnikov AV, Fedotov AK (2014) AC/DC conductance in granular nanocomposite films $\left(\mathrm{Fe}_{45} \mathrm{Co}_{45} \mathrm{Zr}_{10}\right)_{\mathrm{x}}\left(\mathrm{CaF}_{2}\right)_{100-\mathrm{x}}$. J Alloy Compd 586:S353-S356
Kołtunowicz TN, Fedotova JA, Zhukowski P, Saad A, Fedotov A, Kasiuk JV, Larkin AV (2013) Negative capacitance in (FeCoZr)-(PZT) nanocomposite films. J Phys D Appl Phys 46(12): 125304

Mott NF, Davis EA (1979) Electron processes in non-crystalline materials. Clarendon Press, Oxford

Mott NF, Gurney RW (1950) electronic processes in ionic crystals. Clarendon Press, Oxford

Oommen TV (1983) Moisture equilibrium in paper-oil systems. In: Proceedings of the 16th electrical/electronics insulation conference, Chicago, pp 162-166

Pogrebnjak AD, Beresnev VM (2012) Nanocoatings, Nanosystems, Nanotechnologies. Bentham Science, Oak Park

Ravich YuI, Nemov SA (2002) Hopping conduction via strongly localized impurity states of indium in $\mathrm{PbTe}$ and its solid solutions. Semiconductor 36(1):1-20

Shklovsky BI, Efros AL (1984) Elecronic properties of doped semiconductors. Springer, Berlin

Van Vlack LH (1972) Materials Science for Engineers. Addison-Wesley Publishing Company, Boston

Żukowski P, Kołtunowicz TN, Żukowski K, Subocz J, Szrot M, Gutten M (2014) Assessment of water content in an impregnated pressboard based on DC conductivity measurements. Theoretical assumptions. IEEE Trans Dielectr Electr Insul 21(3):1268-1275 